\title{
Rasgos y desafíos de la reciente diplomacia cultural entre India y China
}

\section{Verónica Noelia Flores ${ }^{1}$ \\ USAL-UBA/CONICET}

\section{Artículo científico}

Material original autorizado para su primera publicación en Journal de Ciencias Sociales, Revista Académica de la Facultad de Ciencias Sociales de la Universidad de Palermo

\section{Recibido: 6-8-2017}

Aprobado: 8-8-2017

\section{Resumen}

Este trabajo plantea una aproximación a los vínculos diplomáticos recientes entre India y China a partir de una concepción de la diplomacia cultural como enfoque estratégico de política exterior, en el marco de los nuevos lenguajes de comunicación social e intercambio a nivel global. Se enfoca particularmente en el uso político de las imágenes. Desde esta mirada, el objetivo ha sido indagar de qué modo se han formulado las relaciones diplomáticas recientes entre India y China. Se concede especial importancia al carácter de los encuentros sostenidos entre el Primer Ministro indio Narendra Modi y el Presidente chino Xi Jinping en los últimos tres años, y se considera a su vez de qué manera se han registrado y difundido públicamente estos eventos.

Palabras clave: Política exterior; diplomacia cultural; comunicación social; imágenes.

\begin{abstract}
This paper proposes an approach to the recent diplomatic relations between India and China based on a conception of cultural diplomacy as a strategic foreign policy approach within the framework of the new languages of social communication and exchange at the global level, focusing on the political use of images. From this perspective, the purpose here has been to investigate how recent diplomatic relations between India and China have been formulated, paying particular attention to the nature of the meetings between Indian Prime Minister Narendra Modi and Chinese President Xi Jinping in the last

\footnotetext{
${ }^{1}$ Licenciada en Historia (FFyL, UBA) y Doctoranda en Historia y Teoría de las Artes (FFyL,UBA). Becaria del CONICET. Es Investigadora y Profesora Adjunta regular (USAL). Autora de distintas publicaciones, es también miembro del Grupo de Estudios del Este Asiático (GEEA/ Instituto de Investigaciones Gino Germani, Facultad de Ciencias Sociales, UBA) -siendo Coordinadora en el mismo del Grupo de Estudios sobre China- y del Grupo de Trabajo sobre India y Asia del Sur del Comité de Asuntos Asiáticos del Consejo Argentino para las relaciones Internacionales.
} 
three years, considering in turn how these events have been publicly recorded and disseminated.

Key words: Foreign policy; cultural diplomacy; social communication; images.

\section{Introducción}

En los últimos años, la comprensión del desarrollo de las relaciones internacionales a partir del término "poder blando", acuñado por el politólogo estadounidense Joseph Nye ${ }^{2}$, se ha enriquecido y ampliado, lo que ha logrado acercamientos novedosos desde perspectivas que integran a lo social y político la insoslayable incidencia de los factores culturales (Montoya Ruiz, 2012). Así se ha avanzado en estudiar una de las formas más comunes del llamado poder suave: la diplomacia cultural que "permite a través del intercambio de ideas, información, valores, sistemas, tradiciones y creencias, fomentar el entendimiento mutuo entre naciones" (Montiel, 2010, p. 3). En la nueva era global e intercultural que compartimos, este modelo de gobernanza en la política exterior ha resultado más versátil, flexible y sutil para el manejo y la exteriorización de las relaciones diplomáticas entre naciones, y estableció distancia respecto de otros modelos tradicionales más ásperos o agresivos en las formas corporales y en el discurso comunicativo de funcionarios y líderes (Otero Roth, 2007).

Este modelo de diplomacia cultural se gesta en el seno de cada país y se compone de ciertos elementos: la buena gestión de una imagen positiva exterior; las buenas prácticas en cuanto al uso de los recursos del patrimonio cultural y natural, la riqueza de su diversidad cultural;la agilidad en el propio ajuste y conciliación frente al cambio, y la adaptación y uso de los medios tecnológicos aplicables a la educación y a las ciencias (Gerome, 2012).

El caso de las relaciones entre India y China nos provee un ejemplo interesante para seguir indagando desde este enfoque el desarrollo de nuevas formas y mecanismos de diplomacia y política exterior. En el marco de un orden global cada vez más complejo e impredecible, ha sido notable cómo lo cultural ha permeado en el campo de las relaciones políticas entre ambos países. Este modelo de relaciones necesariamente más armonioso ha jugado un papel relevante como instrumento de diálogo y acercamiento mutuo, aunque también ha dejado entrever ciertas tensiones, dada la vigencia de los conflictos irresueltos e intereses geopolíticos en disputa. Conel fin de explorar nuevos modos y herramientas de análisis para abordar la política exterior de India y China, este

\footnotetext{
${ }^{2}$ Nye (2004) define el concepto de "poder blando" o suave (softpower en inglés) como "la habilidad de obtener lo que se quiere a través de la cooptación y la atracción", en contraste con el "poder duro" que se identifica con el uso de la coerción.
} 
trabajo recupera ciertas imágenes y discursos registrados de las visitas diplomáticas sostenidas en los últimos tres años entre el Primer Ministro indio Narendra Modi y el Presidente chino Xi Jinping. Para ello presentaremos brevemente el carácter de los encuentros entre ambos líderes, el alcance de las medidas tomadas a partir de ellos y finalmente, los desafíos que a nivel geopolítico y económico aún perduran y cuestionan la efectividad e incidencia a corto plazo de la estrategia de diplomacia cultural entre ambos países. Se ha utilizado la revisión bibliográfica y de diversos medios que han difundido las noticias acerca de los encuentros considerados.

\section{Rasgos de la reciente diplomacia cultural entre India y China: las visitas de} carácter oficialy sus registros visuales

\section{1.a) Xi visita India}

Enun gesto notable de acercamiento, en septiembre de 2014, el presidente chino Xi Jinping visitó las ciudades de Ahmedabad y Gandhinagar. Aquel fue su primer viaje a la India desde su asunción en marzo de 2013 y la primera visita diplomática de un presidente chino a este país luego de ocho años. Con esta postura, China inauguraba un nuevo ciclo de relaciones con su vecino país, para poner en marcha una dinámica de cooperación armoniosa y de intercambio recíproco en el crecimiento sostenido de sus economías.

Al llegar a Ahmedabad -la séptima ciudad más poblada de la India y el distrito de mayor importancia del estado de Gujarat, donde Modi había gobernado antes de asumir su cargo como primer ministro -, Xi Jinping declaró:

Es aquí donde el eminente monje chino XuanZang llegó tras su largo viaje en busca de textos budistas durante la dinastía Tang, por lo tanto disfruta de una posición especial en la larga historia de intercambios fraternales entre nuestros dos países.

La observación sobre el enriquecimiento cultural a partir de la continuidad histórica de los intercambios entre ambas naciones fue acompañada por un importante anuncio de inversiones. Así, como resultado de esta histórica visita, Xi anunció que se realizaría una inversión de 20 mil millones USD en la India durante los siguientes cinco años, dirigida sobre todo a impulsar el desarrollo infraestructural del país a partir de la construcción de nuevas y más rápidas líneas férreas, así como una mayor cooperación a nivel comercial dada la condición de mercados emergentes de ambas naciones, que están en busca de consolidar la estabilidad política y de avanzar hacia una relativa prosperidad económica para sus habitantes.

Por entonces, el anuncio manifestaba la búsqueda por parte de ambos países de un desarrollo equilibrado y sostenido de las relaciones comerciales y diplomáticas. Esto se expresó a su vez en la formulación de medidas específicas para mejorar el acceso al 
mercado de productos agrícolas, al farmacéutico y de exportación. A la vez, se permitiría a los productores de ambos países el aprovechamiento de oportunidades para fusionar sus recursos creativos, artísticos, técnicos, financieros y publicitarios. De este modo, se le daría apoyo al crecimiento de determinados sectores, como la industria audiovisual en la India, a ganar mayor presencia en los mercados globales (Unnithan, 2014).

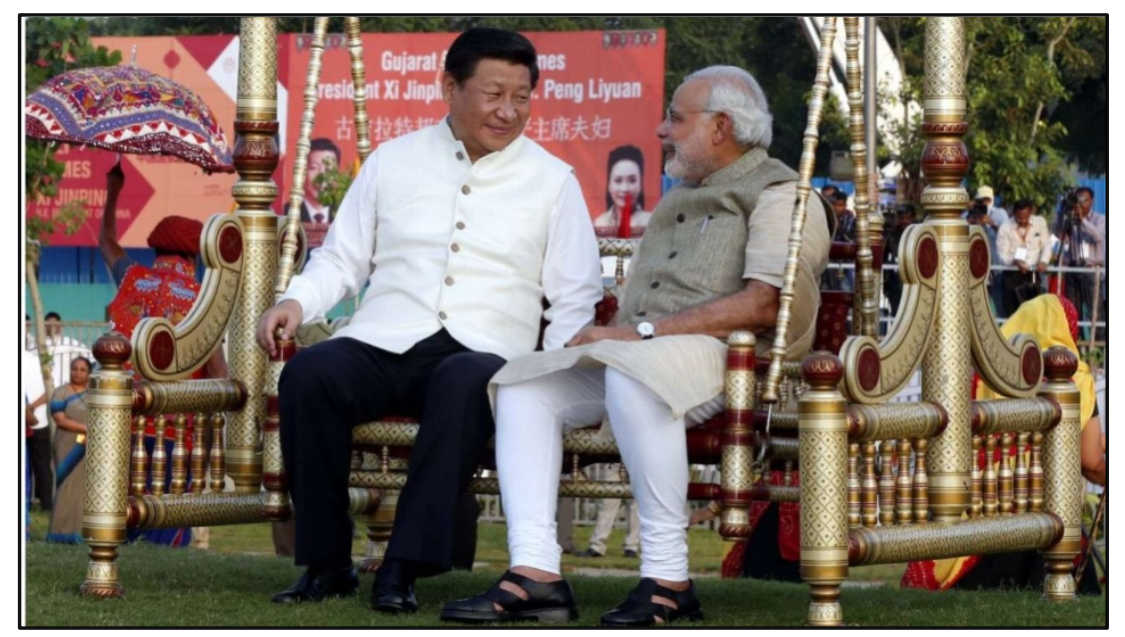

Fig 1. Xi es recibido por Modi en Ahmedabad (Gujarat). Fuente: Xinhua.

Subrayando los fundamentos culturales de esta estrecha relación, decía por entonces el presidente Xi:

La India y China son dos civilizaciones antiguas con miles de años de interacción amistosa entre sí. Cada una admira y respeta a la civilización y cultura de la otra. Es importante que traduzcamos estos contactos amistosos y que nos aseguremos de mantener nuestras promesas la una a la otra.

En este viaje, Xi visitó a su vezSabarmati Ashram, la residencia de Mahatma Gandhi,vestido conuna prenda hilada de khadi, el algodón tejido en las famosas ruecas. Es un símbolo del propio Gandhi y de su programa constructivo de autosuficiencia swadeshi-e interdependencia. 


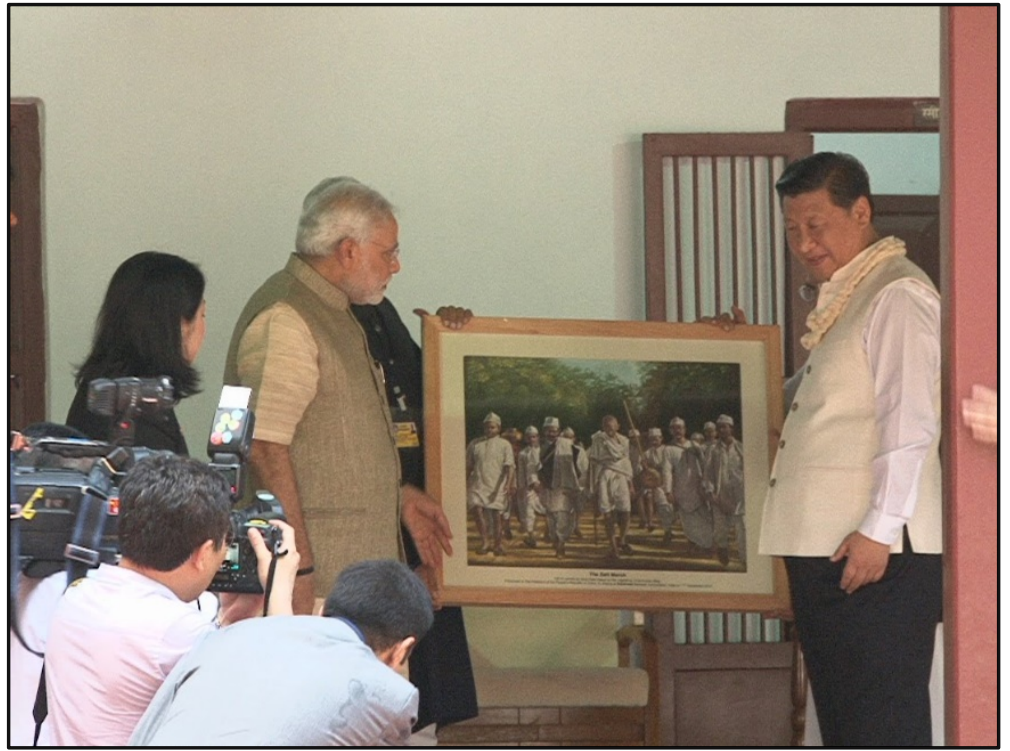

Fig2. Xi Jinping visita SabarmatiAshram, residencia de Mahatma Gandhi. Fuente: Asia

Significativamente, también en el marco del ideario independentista promovido por Gandhi, la rueca representa la dignidad del trabajo, la equidad y la unidad. En una clara evocación de estos ideales, Modi invitó a su par chino a ejecutar el movimiento del giro de la rueda para iniciar el hilado. Las imagenes de este acontecimiento circularon en los medios de comunicación a nivel local e internacional como un signo manifiesto de las intenciones de mutuo reconocimiento y valoración en este nuevo marco decorrespondencia..

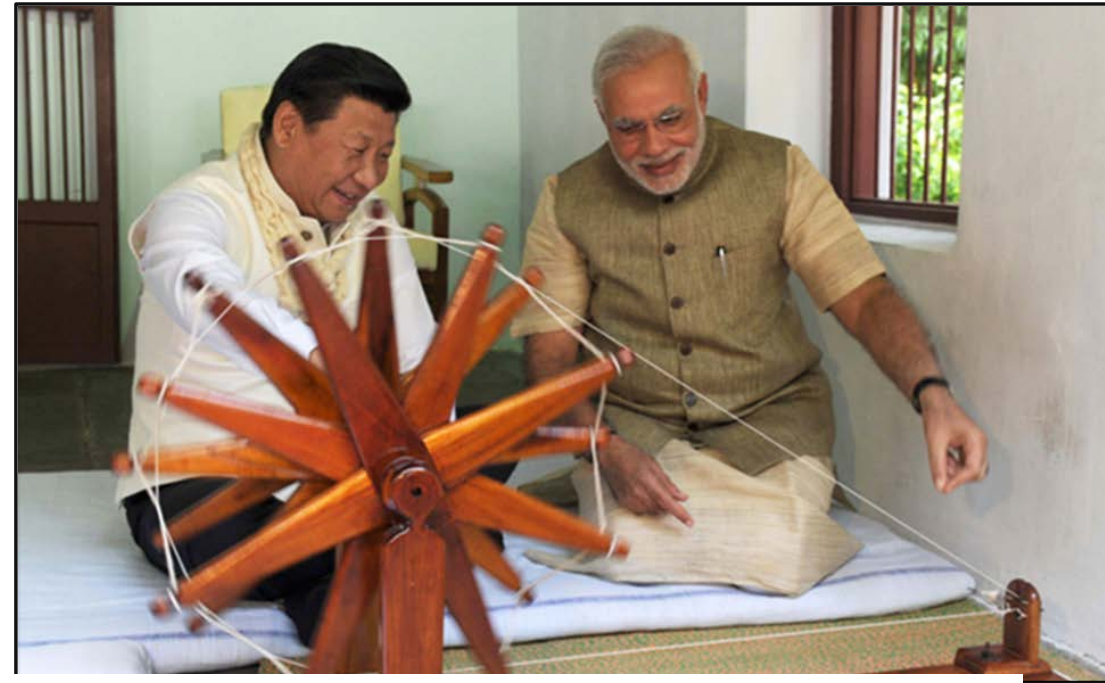

Fig 3.Bajo la guía atenta de Modi, Xi hace girar la rueca (charkha) para hilar khadi, símbolo del programa constructivo de Gandhi. Fuente: The Indian Express.

\section{1.b) Modi visita Chinz}

Como contrapartida, en el desarrollo de esta estrategia de diplomacia cultural, en mayo de 2015 Modi realizó un viaje a China para visitar las ciudades de Xían, Beijing y Shanghai. 


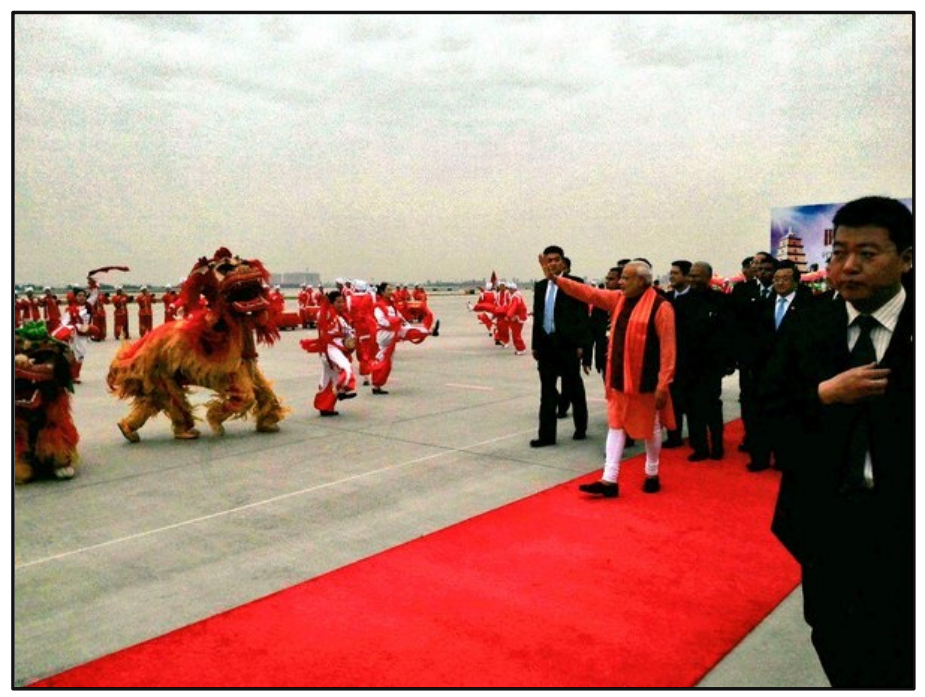

Fig.4. Modi arriba a Xi'an, capital de Shaanxi $y$ renovado centro de poder en el diseño de la nueva Ruta de la seda. Fuente: MEA. India.

En medio de un despliegue importante de artistas, músicos y bailarines de danzas tradicionales, Modi fue recibido con una gran ceremonia en Xían, actual capital de la provincia de Shaanxi, antigua capital de la Dinastía Tang y nuevo centro de poder en el renovado corredor de la ruta de la seda y a su vez provincia natal (lao jia, en mandarín) del propio presidente Xi Jinping.

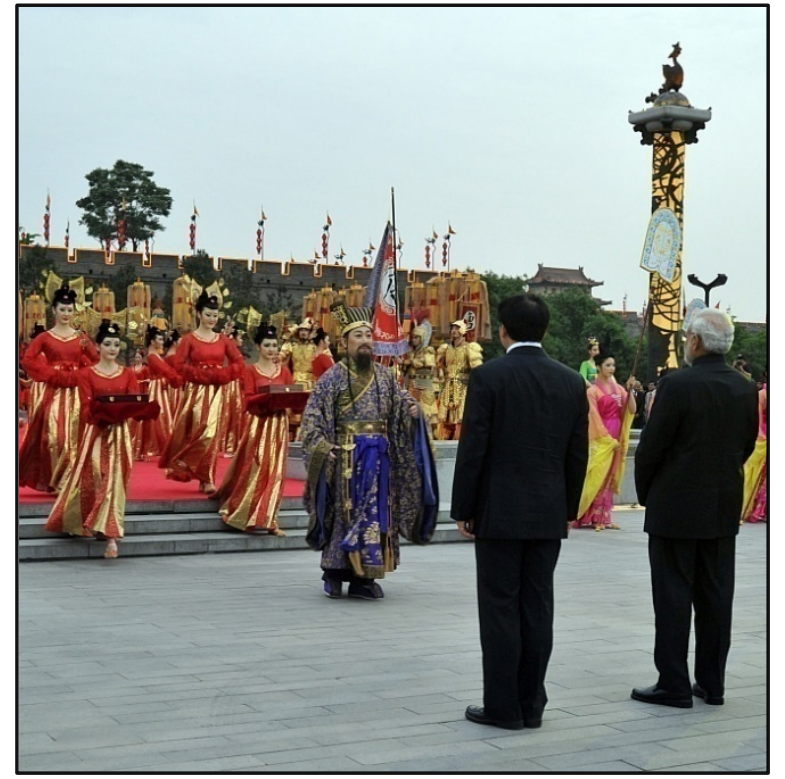

Fig.5. Recepción de Modi en Xían con artistas que representan el estilo ceremonial de la dinastía Tang. Fuente: Xinhua.

En principio, el líder indio fue invitado a conocer a pocos kilómetros de Xían el sitio arqueológico de Guerreros de terracota, donde se conserva la célebre colección escultórica de la armada de Qin Shi Huang, el primer emperador de China. Allí, Modi reconoció "la etapa de desarrollo estable y con amplios prospectos" que ambos países estaban atravesando (Razdan, 2015). 


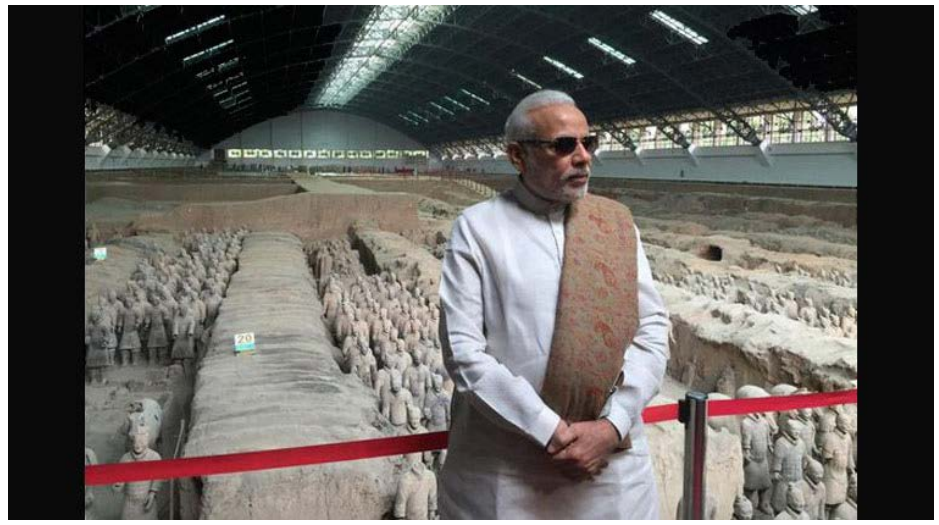

Fig.6. Modi posa en el sitio arqueológico de los Guerreros de terracota en Xi'an. Fuente: China

Modi continuó su recorrido por otro sitio que ejemplifica la herencia cultural clásica del diálogo entre China y la India: el templo budista Da Xingshan-Templo de la gracia maternal-,donde se emplaza la Gran Pagoda del Ganso Salvaje, construida a mediados del siglo VII. Allí se exhiben como tesoros lossutras, cuyas antiguas traducciones del sánscrito al chino fueron realizadas por el monje XuanZang. Este lugar fue en el pasado uno de los nodos en la antigua ruta de la seda y uno de los centros de traducción más importantes de textos budistas en Asia. En la imagen, Modi recibe una estatua dorada de Buddha como obsequio del abad del templo.

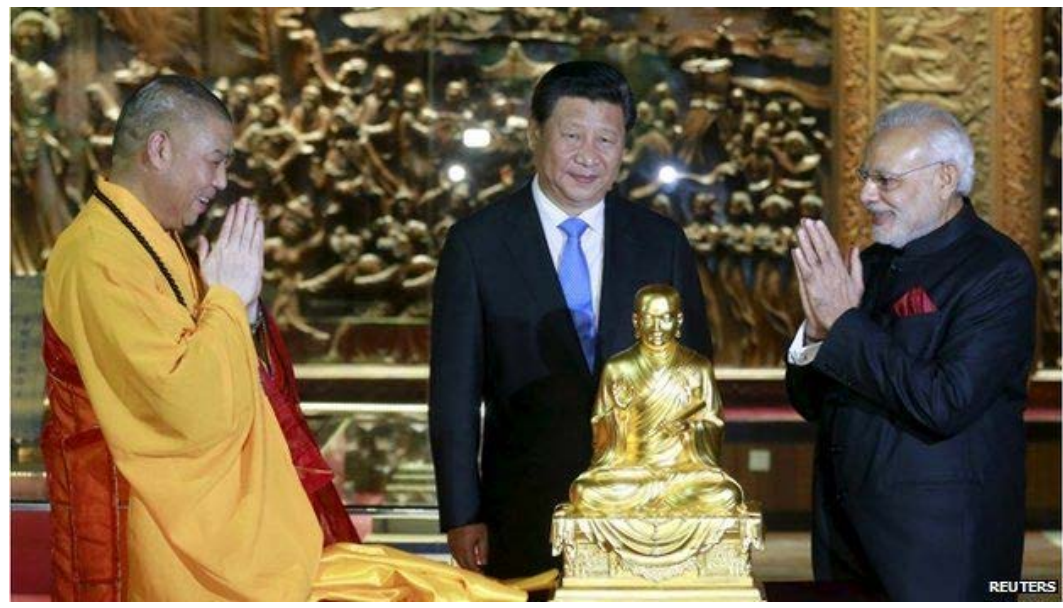

Fig. 7 Modi recibe una estatua en oro de Buddha como obsequio del abad del Templo Da Xingshan, en Xian.

Poco después, como segunda escala en su visita a China, Modi fue recibido por el Primer Ministro Li Keqiang en el Gran Salón del Pueblo en Beijing.Luego visitó entre otros sitios el gran Templo del Cielo. Allí, Modi enfatizó la importancia de las conexiones interpersonales y de la necesidad de reforzar los vínculos culturales. 


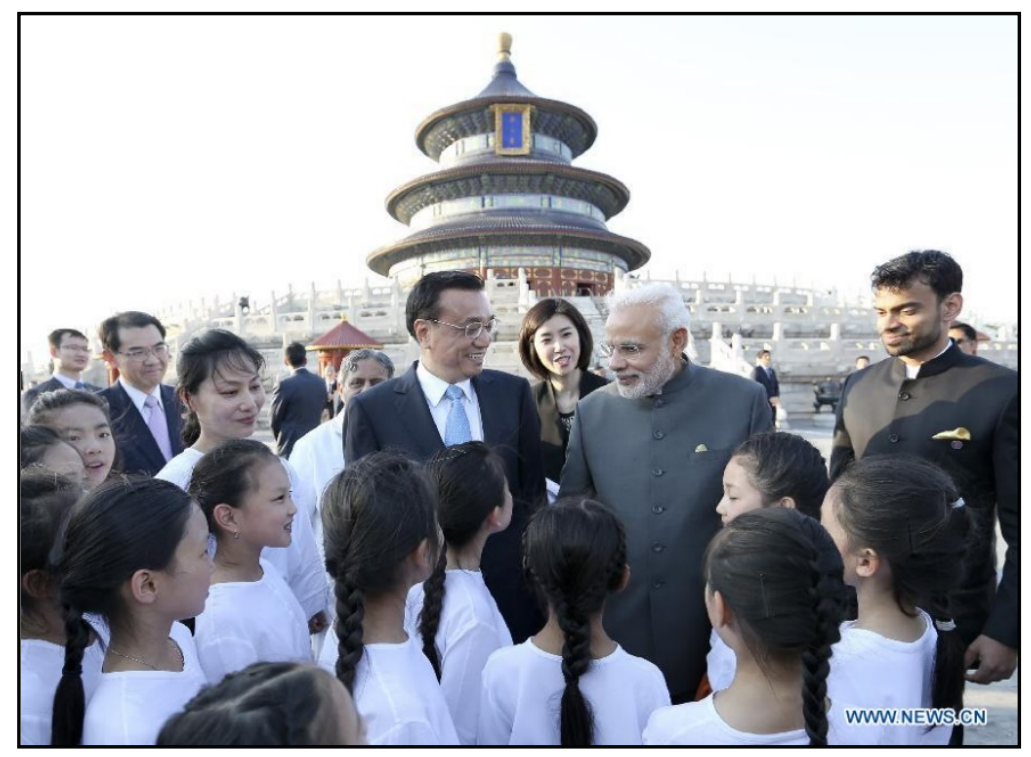

Fig.8 Encuentro con jóvenes frente al Templo del Cielo. Fuente: News.cn.

La intención de fortalecer las relaciones entre ambas se cristalizó en una amplia sesión conjunta de yoga y tai-chi. Montada como un espectáculo que se televisaría en simultáneo en ambos países, un grupo de niños de la India practicaron taichi mientras que otros, chinos, practicaron yoga.

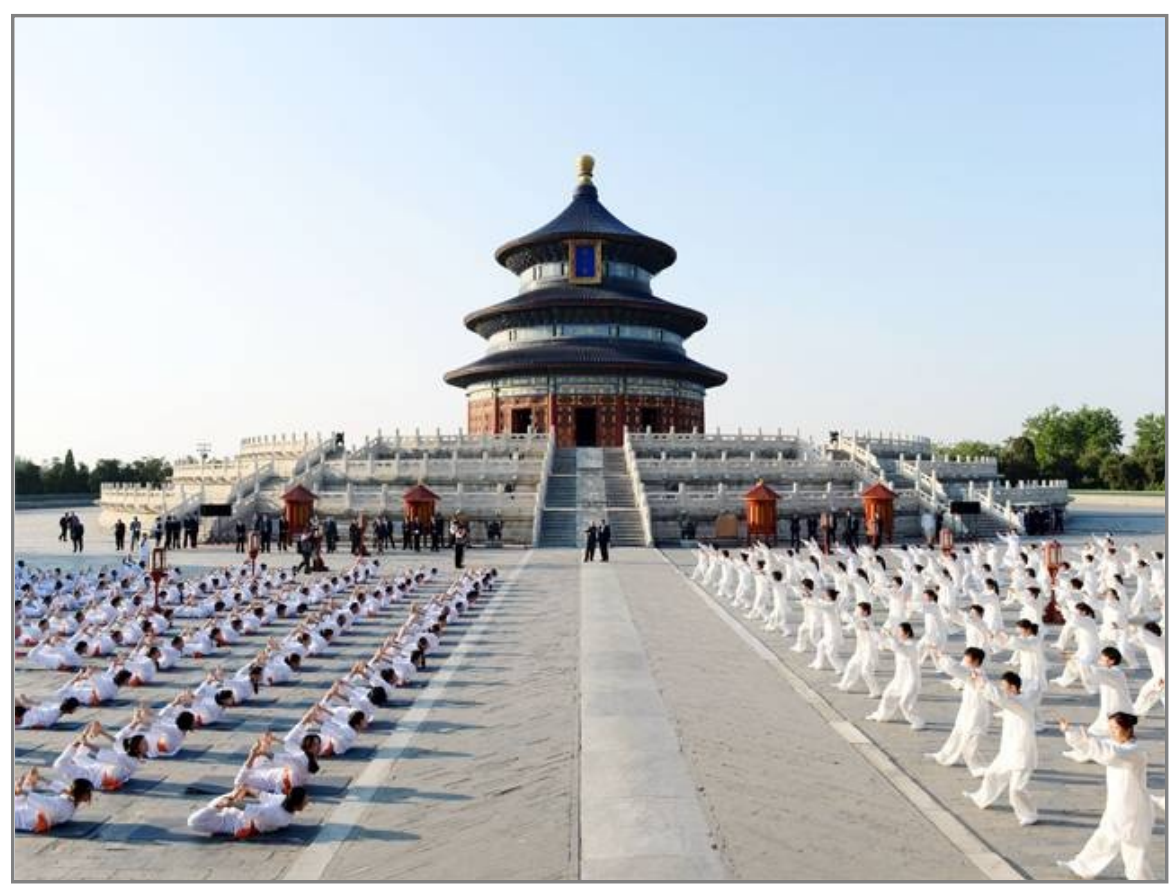

Fig.9 Sesión conjunta de yoga y taichi frente al Templo del Cielo en Beijing.

"Para ganar el cielo -decía Modi en su discurso a los jóvenes que participaron del evento- la mente, el cuerpo y el intelecto deben estar en perfecto balance". El primer ministro indio reconoció la ayuda de China en las Naciones Unidas para la adopción del 21 
de junio como el Día Internacional del Yoga: "En septiembre pasado, cuando presenté la propuesta en la ONU, 177 países lo apoyaron y China en particular ofició de copatrocinador de la India". En el cierre, Modi ratificó la necesidad de fortalecer el "contacto entre personas y las conexiones culturales" a través del conocimiento mutuo y de implementar la comunicación de sus potencialidades de forma colectiva (Jiwrajka, 2015).

Si bien el acceso a las redes sociales Facebook y Twitterestá restringido desde China, Modi reprodujo en sus cuentas la instantánea con el primer ministro chino. Esta imagen fueen pocas horas una de las más vistas y compartidas en India.

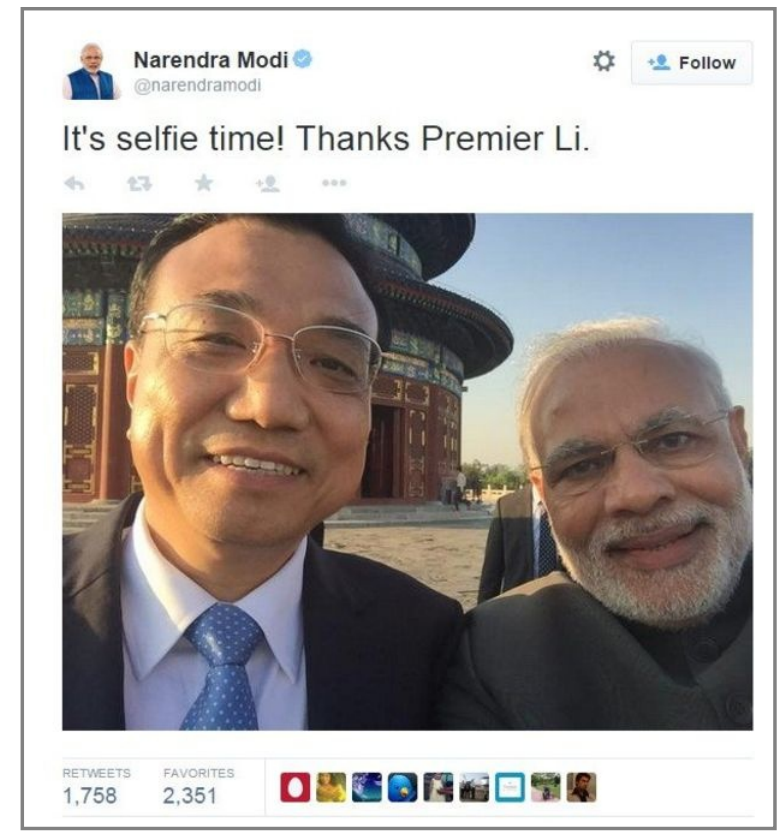

Fig.10 Imagen publicada por Modi en su cuenta deTwitter.

Luego de este evento, se firmaron varios acuerdos: el establecimiento de un centro de estudios sobre la figura de Gandhi y sobre la India en la Universidad de Fudan (Shanghái); la creación de un laboratorio de ideas bilateral, y la colaboración para la apertura de nuevas escuelas de yoga en Kunming y Yunnan. Además, para potenciar la interacción y el conocimiento mutuo entre individuos, así como para favorecer el turismo entre ambos países, Modi anunció el otorgamiento de visas electrónicas a turistas chinos para estimular las iniciativas "Visite la India" de 2015 y "Visite China" de 2016.

A partir de este encuentro, ambos hicieron explícita la necesidad de una política exterior entre los estados y las provincias de ambas naciones, priorizando la noción de un "enfoque honesto y constructivo" para sortear los obstáculos que aún se oponen al potencial de esta asociación. Se anunció que se revisaría la política de emisión de visasgrapadas a residentes de Jammu, Cachemira y Arunachal Pradesh, así como el apoyo mutuo en el fomento de la urbanización, y la cooperación de China en la iniciativa industrialista de Modi planteada en el eslogan "Make in India". 
Finalmente, en la última escala de su recorrido por China, Modi participó del Foro de Jefes Ejecutivos de la India y China, donde se reunió la comunidad de negocios de ambos países. Allí se enfatizó la importancia de la interacción entre líderes y empresarios de estados o provincias de ambas naciones.

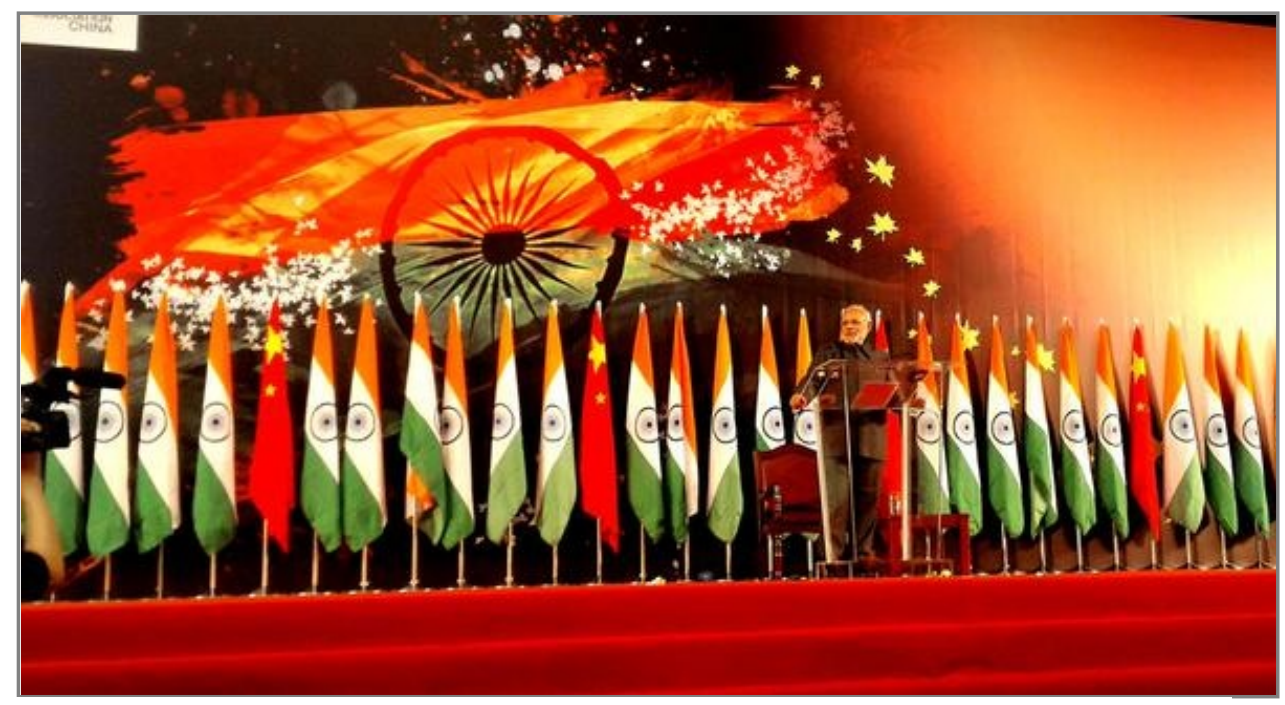

Fig.11 Modi en el Foro de Jefes Ejecutivos de la India y China en Shanghai. Fuente: China Daily.

En este foro se firmaron acuerdos comerciales por un valor de 22 mil millones USD, compromiso que ya había asumido Xi en su visita a India. Bajo este marco, se diseñaron planes quinquenales que consoliden el diálogo bilateral hacia un plan estratégico de comercio y desarrollo conjunto. Así, se acordó el establecimiento de dos parques industriales en Gujarat y en Maharastra por parte de China, y la cooperación en proyectos de ferrocarriles -incluido el aumento de la velocidad en la línea Chennai-BangaloreMysore, estudios de viabilidad para la sección Delhi-Nagpurdel enlace férreo de alta velocidad, y el establecimiento de una universidad del Ferrocarril en Nueva Delhi-.

Asimismo, se planteó el compromiso de entablar una relación de cooperación entre las "ciudades hermanas" de Guangzhou y Ahmedabad, y entre las provincias de Gujarat y Guangdong. Bajo este modelo que está consolidándose, se formuló hermanar otras ciudades-Bombay y Shanghai, Hyderabad y Qingdao, Aurangabad y Dunhuang, Chennai y Chongqing—así como estados o provincias_-además de Gujarat y Guangdong, Karnataka y Sichuan-.

\section{A través de las imágenes: diplomacia cultural, negocios y geopolítica}

Dada la importancia del carácter cultural de la diplomacia reciente entre China e India, en las imágenes que vimos, se han destacado ciertos aspectos como estrategias para 
reforzar esta cooperación emergente, que coordina de manera simultánea diplomacia, cultura, negocios y geopolítica.

Entendemos desde la perspectiva semiótica de Eco que "no todos los fenómenos comunicativos pueden ser explicados por medio de categorías lingüísticas". Por lo tanto, para comprender su mensaje es preciso abordar las imágenes como signos motivados, que "se enraízan en lo real" a partir de elementos que funcionan como "códigos de reconocimiento" (1986, pp. 167-174)

En las primeras visitas, se resaltaron los vínculos de la civilización de ambos países, y se destacó la antigüedad y persistencia de los contactos e intercambios culturales como rasgos de una asociación recíproca y complementaria. Se enfatizó la importancia del contacto entre personas y el valor de la historicidad de las conexiones culturales.

Según la línea diplomática oficial de China, la estrategia de desarrollar y renovar la cultura tiene dos caminos posibles en el siglo XXI: el "dar la bienvenida" y el "salir a buscar". Entre ambas vías, la segunda es la que tiene mayor relevancia ya que "para conseguir que la cultura china tenga presencia en el extranjero, es necesario desarrollar el comercio con otros países" (Meng, 2004).

Negocios, geopolítica y cultura son factores de mutua incidencia en el campo de las relaciones exteriores de ambos países. Estos elementos han permitido construir en los últimos dos años el entramado de una nueva narrativa delas relaciones diplomáticas entre India y China. Es una visión que reduce los antagonismos políticos y promueve la afirmación cultural y económica de ambos países como socios emergentes clave y protagonistas activos de la recomposición del escenario global.

Este relato, como vimos, no se sostiene sólo en el alcance de las declaraciones verbales, sino en la potencialidad de las imágenes. A partir de la selección presentada en el apartado anterior, vimos cómo las fotografías -como instrumento de registro y selección de la memoria colectiva- muestran las expectativas de ambos países, pero también el silencioso propósito de invisibilizar la tensión en las relaciones de fuerza. Su impacto se reproduce al tiempo que circulan y atraviesan fronteras para fortalecer la construcción discursiva y el gesto corporal de los líderes políticos. En este sentido, el uso político de las imágenes -tanto testimonios vívidos como datos cuidadosamente producidos- es el mecanismo que refuerza en su difusión a escala mundial este relato comunicacional sobre las intenciones de acercamiento, diálogo y cooperación en beneficio mutuo.

\section{Palabras finales: Algunos desafíos a este modelo de diplomacia}

Como desafíos de esta estrategia de diplomacia cultural, donde claramente la cultura une lo que la política separa, permanecen las irresueltas diferencias reales entre los intereses en pugna. Más recientemente, en septiembre de 2016, Modi visitó China en 
ocasión de la Cumbre de líderes mundiales del G-20, realizada en la ciudad de Hangzhou. A diferencia de las ocasiones anteriores, esta visita fue registrada con menor impacto, dado que se produjo en el contexto de una escalada de tensión por las diferencias geopolíticas en el océano Indico y por el conflicto persistente en torno al Corredor Económico entre China y Pakistán (CPEC), al igual que por la renuente actitud de China de apoyar la solicitud de India para ser incluida en el Grupo de proveedores nucleares (NSG).

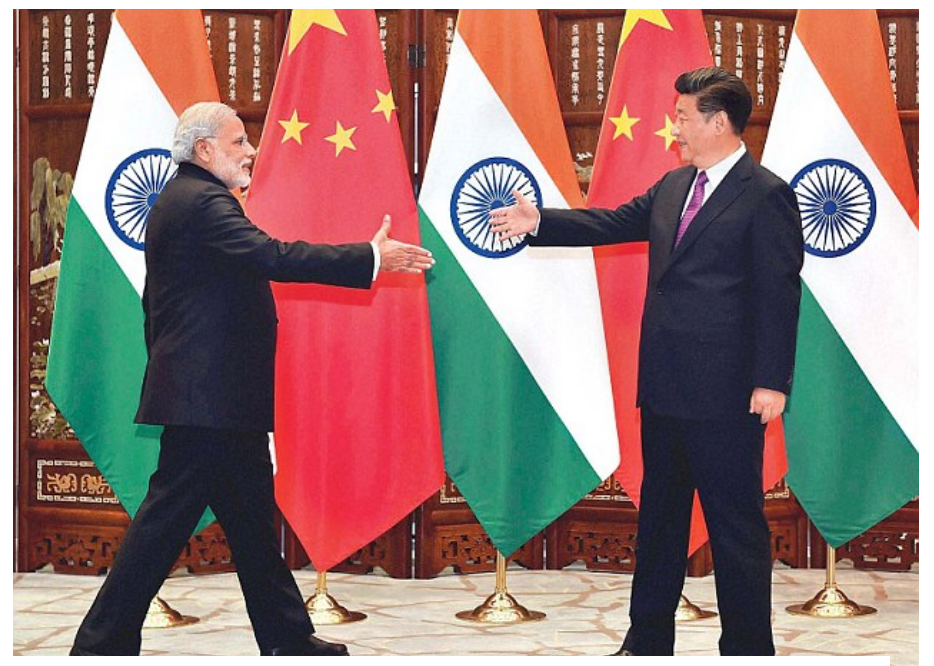

Fig.12. Encuentro en el marco de la Cumbre del G-20 en Hangzhou. Fuente: PTI.

Asimismo, tuvo poca difusión en imágenes la visita reciente de Xi Jinping a la Cumbre de los BRICS en Goa el 15 de octubre de 2016, donde el fantasma del terrorismo y del conflicto por la línea de control en la frontera con Pakistán reapareció, lo que perturbó las apreciaciones de ambos líderes (Chowdhury, 2016).

Los desafíos futuros se plantean por una parte desde la necesaria resolución de las disputas fronterizas -en el reclamo de China sobre Arunachal Pradesh y de India sobre Aksain Chin—con el fin de lograr un verdadero apoyo para las iniciativas de cooperación y desarrollo conjunto (Chand, 2016).Esto a su vez implica el reconocimiento formal de la necesidad de establecer vías para la pacificación en otras áreas en conflicto como Cachemira, Assam yTibet. Tal impulso a la resolución de estos conflictos históricos implicaría como desafío la creación o profundización de alternativas institucionales para una mejor gobernanza a nivel regional y global.

Es difícil aún predecir o evaluar el alcance que las nuevas formas de diplomacia cultural tendrán corto o largo plazo. En términos culturales, los desafíos de esta reciente política suponen la maduración de una "estrategia comunicativa" que vaya más allá de los meros anuncios formales, y que tienda a una efectiva integración y a un desarrollo equilibrado, para combinar la exposición de las propias fortalezas sin atacar las aspiraciones del otro. 
En estos nuevos esfuerzos de cooperación e intercambio entre personas e instituciones probablemente contribuyan, como aquí hemos visto, no sólo la fuerza del discurso de los propios líderes políticos sino también el potencial de las imágenes que los acompañan o los exceden incluso en su capacidad de difusión. Así, se generan, desde lo cultural, nuevos sentidos en la traducción del otro, así como nuevas formas de vinculación y diálogo entre los países.

\section{Referencias bibliográficas}

AAVV. (2015) Modi's China visit: Among monks and Warriors. Recuperado de http://www.rediff.com/news/report/pix-enter-the-dragon-pm-modi-inchina/20150514.htm

Chand, M. (2016). Diseñando el BRICS: centrado en las personas, innovador e inclusivo. EnIndia Perspectives, Nro. 7, pp-7-14.

Chowdhury, D. (2016). China-India-Pakistan Triangle: When Xi meets Modi, a little less love this tima. Recuperado de http://www.scmp.com/weekasia/geopolitics/article/2028157/when-xi-meets-modi-little-less-love-time

Eco, U. (1986). La estructura ausente. Introducción a la Semiótica. Barcelona: Ed. Lumen.

Gerome, E. (2012). Evolution of cultural diplomacy. Recuperado de http://www.culturaldiplomacy.org/pdf/case-studies/Gerome-Evolution-of- culturaldiplomacy.pdf.

Jiwrajka, S. (2015).Narendra Modi to visit China, Mongolia, \& Republic of Korea: Complete Schedule. Recuperado de http://www.india.com/news/india/narendramodi-to-visit-china-mongolia-republic-of-korea-complete-schedule-382293/

Meng, X. (2004) The Mission of Chinese culture in the age of Peace and Development. Li Lun (Teoría).

Miranda, E. (2016). La diplomacia cultural de China: poder suave de alcance global. Recuperado de http://elordenmundial.com/2016/05/17/la-diplomacia-culturalchina-poder-suave-alcance-global/

Montiel, E. (2010), Diplomacia cultural, Un enfoque estratégico de política exterior la era intercultural. Cuadernos UNESCO Guatemala Cultura y Vida, Nro. 2, Guatemala: UNESCO.

Montoya Ruiz, S. (2012). La redefinición de la diplomacia cultural en el mundo contemporáneo. Oasis, 17, 165-202.

Nye, J. (2004). The means to success in World Politics, New York: Public Affairs.

Otero Roth, J. (2007). China descubre la diplomacia pública.Anuario Asia Pacífico 2007. España: CIDOB-RIE.

Razdan, N. (2015). "Highest-Level Reception' for PM Modi in China as President Xi Skips Protocol". Recuperado de http://www.ndtv.com/india-news/pm-modiarrives-in-chinas-xian-president-xi-jinpings-hometown-762932

Swarup V. (2015). Chinese President Xi Jinping's India visit: After six decades, a Chinese leader gets public welcome. Recuperado de 
http://timesofindia.indiatimes.com/india/Chinese-President-Xi-Jinpings-India- visitAfter-six-decades-a-Chinese-leader-gets-publicwelcome/articleshow/42741311.cms

Unnithan, Ch. (2014). China mulls industrial park in Gujarat. Recuperado de http://timesofindia.indiatimes.com/business/india-business/China-mulls- industrialpark-in-Gujarat/articleshow/42392371.cms 